\title{
ANALISIS PENGARUH INFILL OVERLAP TERHADAP KARAKTERISTIK PRODUK HASIL 3D PRINTING DENGAN MENGgUNAKAN MATERIAL POLY LACTIC ACID (PLA)
}

\author{
Fajri Sri Ardion $^{1}$, Heru Sukanto ${ }^{1}$, Joko Triyono ${ }^{1}$ \\ ${ }^{1}$ Teknik Mesin - Universitas Sebelas Maret \\ e-mail address: herusukanto@staff.uns.ac.id
}

Keywords:

Rapid Prototyping, FDM, PLA, Infill Overlap,

\begin{abstract}
:
Rapid prototyping or commonly known as additive manufacturing uses metal and non-metal semi-liquid materials which are compacted layer by layer. Fused deposition modeling (FDM) is one of the methods in the additive manufacturing process that uses thermoplastic filaments (PLA and ABS). Poly Lactic Acid (PLA) or poly lactic acid is an organic plastic or bioplastic made from renewable biomass sources such as corn starch, pea starch and vegetable oils. Important factors affecting the quality of $3 D$ Printing results are nozzle diameter, nozzle temperature, bed temperature, infill patern, infill percentage, print speed, layer thickness and infill overlap. Infill overlap is the percentage of overlapping processes of the filament during the printing process. This research was conducted to determine the effect of infill overlapon the physical and mechanical properties of $3 d$ printing products. The infill overlapvariations used are 0\%, 25\%, 50\%, and 75\% of the nozzle diameter. $50 \%$ variation shows better quality when compared to other variations for density test, tensile test, and bending test.
\end{abstract}

\section{INTRODUCTION}

In this modern era, technological development cannot be avoided and is an indicator of the progress of a country. The technology developed aims to help and facilitate human work, especially in the field of mass production. In addition to the technology industry also began to be developed to fulfill lifestyle and health. Indonesia is one country that is in need of medical devices with a large medical device market potential in Indonesia, reaching $6 \%$ of GDP [1].

Meeting the needs of medical devices in Indonesia still depends on imports from other countries, so research is needed to increase the independence of the production of medical devices. Additive manufacturing or rapid protoyping is a technology that is very instrumental in the manufacturing world. According to Rinanto [2], the additive manufacturing process is often used in industry because in its use it can minimize the presence of parts wasted during the production process. The dimensions of the product resulting from this process are assessed according to the profile of Indonesians [1]. According to Putra [3] the process of rapid prototyping, also known as the three-dimensional printing process (3D printing), was developed in 1981 by Hideo Kodama. At that time, the printing process uses ultraviolet $n$ plastic materials to make 3-dimensional objects. A 3D printer machine that could operate properly was first made in 1984 by Chuck Hull of 3D System Corp. Techniques in rapid prototyping include selective laser sintering, stereolithography apparatus (SLA), digital light processing (DLP), electronic beam melting (EBM), selective laser melting (SLM), and fused deposition modeling (FDM). Fused deposition modeling (FDM) or what is often referred to as fused filament fabrication (FFF) is a technique that is often used. According to Levchenko [4]. FDM was discovered by S. Scott Crump in 1988. In 1990 Fused deposition modeling (FDM) was introduced and commercialized by a 3D printer company called Stratasys. FDM is a printing process that uses thermoplastic filaments (PLA and ABS) as the basic ingredients of the $3 \mathrm{D}$ printing process.

The thermoplastic filament used has a hardened elastic nature, then is heated to the melting point [5]. Warming is done on the nozzle which is then arranged layer by layer (layer by layer) on a platform. After a layer is formed, the extruder will rise and form a new layer above it. This process is repeated until the product is formed according to the design that has been made.

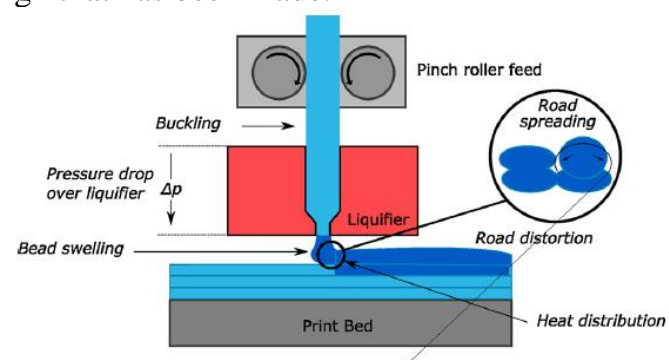

Figure 1. FDM scheme [6]

An important factor affecting the quality of $3 \mathrm{D}$ Printing results is the filament used. The filament 
that is often used is Poly Lactic Acid (PLA). PLA is an organic plastic or bioplastic made from renewable biomass sources such as corn starch, pea starch and vegetable oil that was discovered by Carothers (DuPont) in 1932. In the health PLA can be used in the manufacture of organ implants. Apart from being an implant in PLA organs, it can also be used to make bone support. This can be done by making a mixture of PLA and carbohydrates (cHA) [7]

In 2018, Rajpurohit [8] conducted research on the effect of infill angle, infill width, and layer height on the tensile strength value of 3DP products using PLA material. Based on the research results obtained at an angle of $45^{\circ}$ has the highest tensile strength. At 0.3 $\mathrm{mm}$ layer thickness produces the highest tensile strength value compared with 0.1 and $0.2 \mathrm{~mm}$ thickness, while for $0.5 \mathrm{~mm}$ layer width produces the highest tensile strength value compared to 0.4 and $0.6 \mathrm{~mm}$ layer width. This shows the value of the tensile strength is influenced by the density of the product, the closer the void or overlap produced the smaller the tensile strength and the higher the tensile strength.

Based on research that has been done, extrusion density greatly affects the characteristics of 3D printing products. Therefore, it is necessary to do research on extrusion density or infill overlap. In this study the variable used is the percentage of infill overlap to determine the effect of density on the physical and mechanical properties of 3D printing products using poly lactic acid (PLA) material.

\section{METHODOLOGY}

This study uses 4 variations of overlap infill that is $0 \%, 25 \%, 50 \%$, and $75 \%$ of the nozzle diameter. A Machine used for printing is the Creality Ender 3 type which has a print area of $220 \times 220 \times 250 \mathrm{~mm}$ and is also equipped with an LCD monitor as a control unit. This printer has a built-in nozzle with a diameter of $0.4 \mathrm{~mm}$ and is capable of printing at speeds of up to $200 \mathrm{~mm} / \mathrm{s}$ and can print with a precision of $+/-0.1 \mathrm{~mm}$. The material used in this study was PLA with a $1.75 \mathrm{~mm}$ filament diameter. Material characteristics are sought by conducting several tests including density test, tensile test and bending test.

Specimen preparation refers to several parameters as in table 1 below

\begin{tabular}{|l|l|l|}
\hline no & Variabel tetap & Nilai \\
\hline & Diameter nozzle & $0.4 \mathrm{~mm}$ \\
\hline 1 & Persentase layer thickness & $25 \%$ dari diameter nozzle \\
\hline 2 & Temperatur nozzle & $220^{\circ} \mathrm{C}$ \\
\hline 3 & Temperature bed & $60^{\circ} \mathrm{C}$ \\
\hline 4 & Printing speed & $80 \mathrm{~mm} / \mathrm{s}$ \\
\hline 5 & Infill percentage & $100 \%$ \\
\hline 6 & Infill patern & Lines \\
\hline
\end{tabular}

\section{a.Density Test}

Density testing is used to compare actual density with theoretical density. In this test using a specimen with a size of $127 \times 12.7 \times 3.17 \mathrm{~mm}$. This density test uses a digital balance to determine the mass of specimens in air and water. This mass measurement is used to determine the ratio of mass in air and in water or so-called specific grafity. The density value of the specimen can be calculated by the following

equation.

$$
\rho_{p}=\frac{m_{a}}{m_{a}-m_{f l}} \cdot \rho_{f l}
$$

where, $\rho \mathrm{p}=$ Part density $(\mathrm{g} / \mathrm{ml}) \mathrm{ma}=$ Mass in air (g) $\mathrm{mfl}=$ mass in fluid $(\mathrm{g}) \rho \mathrm{fl}=$ Fluid density $(\mathrm{g} / \mathrm{ml})$

\section{b.Tensile Test}

Tensile testing is a test of the mechanical properties of a material to determine the tensile strength value of a material with the ASTM D638 standard, where this test is intended for rigid plastics. The tool used is the same as the tool for bending test namely Universal Testing Machine (UTM). The shape of the specimen is shown in figure 2.

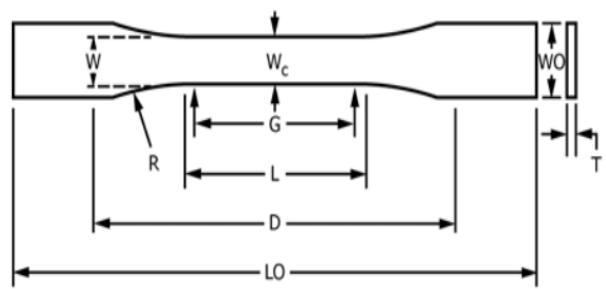

Figure 2. tensile test specimens [9]

where

$$
\begin{aligned}
\mathrm{W} & =13 \mathrm{~mm} \\
\mathrm{~L} & =57 \mathrm{~mm} \\
\mathrm{Lo} & =165 \mathrm{~mm} \\
\mathrm{G} & =50 \mathrm{~mm} \\
\mathrm{D} & =115 \mathrm{~mm} \\
\mathrm{R} & =76^{\circ} \\
\mathrm{T} & =3.2 \mathrm{~mm}
\end{aligned}
$$

Tensile testing is used to determine the tensile strength value of the printed product. To find the data

you can use the equation below:

$$
\sigma=\frac{P}{A}
$$

with: $\sigma=$ tension $(\mathrm{MPa}), \mathrm{P}=\operatorname{load}(\mathrm{N}), \mathrm{A}=$ shear area $\left(\mathrm{mm}^{2}\right)$

\section{c.Bending Test}

Bending testing is carried out to determine the bending / bending strength value of a material with ASTM D790 standard. The dimensions of the specimen used for the bending test are shown in Figure 3. 


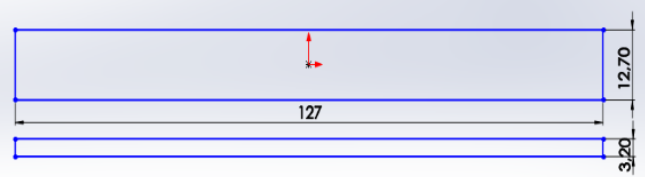

Figure 3 . bending test specimens

The bending strength can be calculated using the following equation.

$$
S=\frac{3 P L}{4 b d^{2}}
$$

Where: $\mathrm{S}=$ Bending Strength (MPa), $\mathrm{P}=$ Maximum Force $(\mathrm{N}), \mathrm{L}=$ Support $\operatorname{span}(\mathrm{mm}), \mathrm{b}=$ specimen width $(\mathrm{mm}), \mathrm{d}=$ specimen thickness $(\mathrm{mm})$

\section{RESULTS AND DISCUSSION} a.Density Test Results

Figure of the results of density testing with variation in overlap infill percentage is shown in Figure 4.

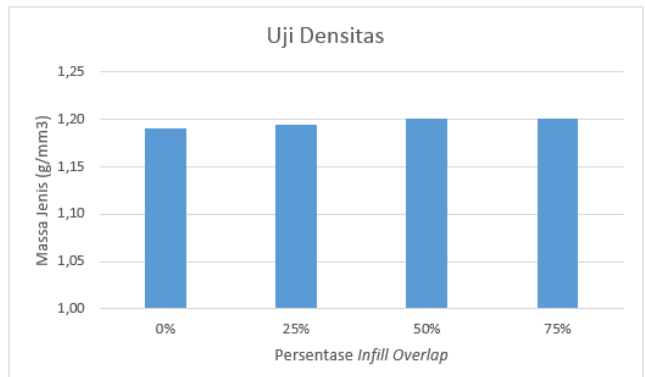

Figure 4. Results of PLA 3D printing product density test

Figure 4. shows the density value of the resulting product has increased from variation of $0 \%$ to $50 \%$. The $50 \%$ variation parameter produces the highest density with a value of $1201 \mathrm{~g} / \mathrm{mm}^{3}$, while the lowest density occurs at a variation of $0 \%$ with a value of $1,191 \mathrm{~g} / \mathrm{mm}^{3}$. An increase in density indicates that the product is getting denser. The density value is influenced by voids or cavities formed in the product, the more voids in the product, the lower the density value. $75 \%$ variation parameters indicate the density values that tend to be the same. The large value of density due to various factors, including the poor arrangement of filaments can cause more voids as shown in Figure 5. The density value of each variation is still close to the density value of pure PLA as said by Farah [10] ie $1.252 \mathrm{~g} / \mathrm{mm}^{3}$.
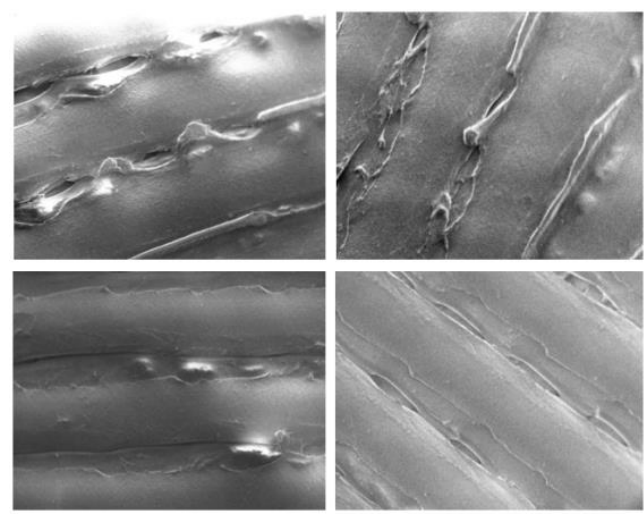

Figure 5. surface of a PLA 3D printing product

\section{b. Tensile Test Results}

Image of the results of tensile testing with variations in the percentage of overlap infill is shown in Figure 6.

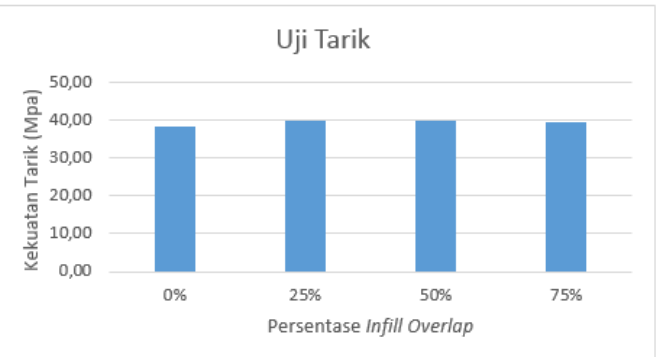

Figure 6. Tensile test results of PLA 3D printing products

Figure 6.shows the value of tensile strength increases with increasing percentage of infill overlap, but has decreased at $75 \%$ variation. The lowest tensile strength value at $0 \%$ variation was $38.41 \mathrm{MPa}$, while the highest tensile strength value occurred at $50 \%$ variation of $40 \mathrm{MPa}$. This is because the void formed is less and less, while in the variation of $75 \%$ the value of tensile strength has decreased with a value of $39.39 \mathrm{MPa}$. This is due to the decreasing density value even though the decrease of the density value is not too large as shown in Figure 7. The greatest tensile strength value at $50 \%$ variation approaches the pure PLA tensile strength value of $59 \mathrm{MPa}$.
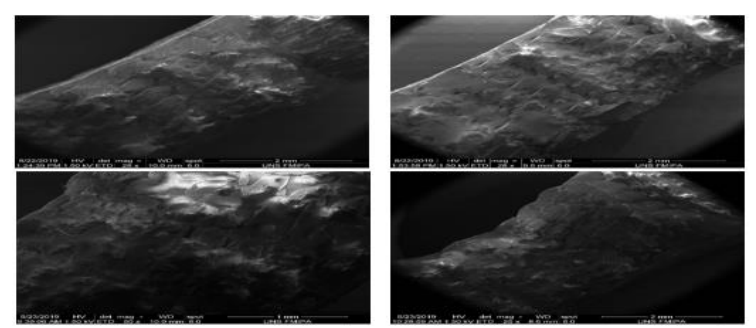

Figure 7. tensile test faults

\section{c. Bending Test Results}

Image results from tensile testing with variation in overlap infill percentage is shown in Figure 8. 


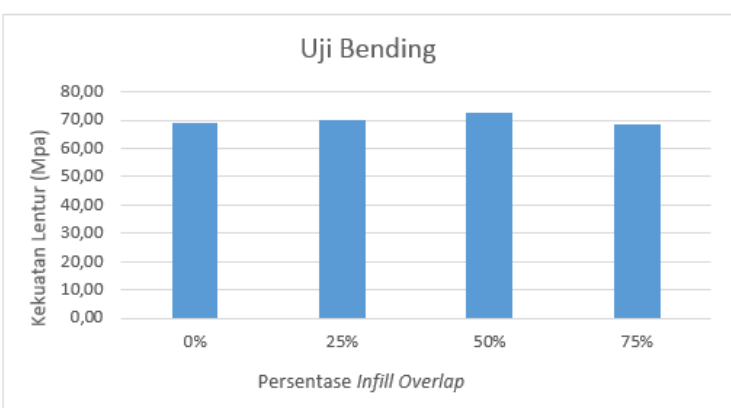

Figure 8. Results of PLA 3D printing product flexural test results

Figure 8. shows the value of flexural strength that increases with increasing percentage of infill overlap, but decreases at $75 \%$ variation. The lowest tensile strength value at $75 \%$ variation was 68.38 $\mathrm{MPa}$, while the highest tensile strength value occurred at $50 \%$ variation of $72.46 \mathrm{MPa}$. The increase in the value of flexural strength corresponds to an increasing density value from $0 \%$ to $50 \%$ variation. This is because the void formed is less and less, while in the variation of $75 \%$ the value of tensile strength has decreased. This is because the density value decreases even though the decrease of the density value is not too large. The highest value of flexural strength in the $50 \%$ variation reached $68.4 \%$ of the value of pure PLA bending strength that is equal to $106 \mathrm{MPa}$.

\section{CONCLUSION}

This study aimed to determine the characteristics of 3D printing products, namely physical and mechanical properties. The variation parameters used are the percentage of infill overlap $0 \%, 25 \%, 50 \%$, and $75 \%$ of the nozzle diameter. The characteristics of $3 \mathrm{D}$ printing products can be determined by conducting several tests, including density, tensile, and bending tests. The tests carried out refer to ASTM D792 testing standards for density testing with Archimedes law, ASTM D638 for tensile tests, and ASTM D790 for bending tests. Based on the testing that has been done, 3D printing products with variation parameters of overlap infill percentage have lower characteristic values when compared to the characteristics of pure PLA.

Factors affecting the quality of the product include the composition and density of the filament during the extrusion process. This is because the density of the product will affect the amount of voids or cavities formed in the product. Too many voids will cause the characteristics of the product is not good and vice versa, the number of voids that are small causes the product quality to get better. Research with variations in the percentage of infill overlap shows the characteristics of a good product is a variation of $50 \%$. This is because all tests show an increase in quality from $0 \%$ to $5 \%$ variation, whereas $75 \%$ variation shows poor product characteristics. Based on research shows that the percentage of overlap infill that is too large can damage the walls of the product and can cause a decrease in product quality.

\section{REFERENCES}

[1] Dini Cahyandari, "Review: Rapid Prototyping Technology Untuk Aplikasi Pembuatan Implan Tulang Dan Gigi 1 Abstrak," vol. 16, no. 1, pp. 35-41, 2016.

[2] A. Rinanto, W. Sutopo, "Perkembangan Teknologi Rapid Prototyping: Study Literatur," J. Metris, vol. 18, pp. 105-112, 2017.

[3] S. Kumara, S. Putra, M. A. Ds, R. Sari, and S. Ds, "Seminar Nasional Sistem Informasi dan Teknologi Informasi 2018 SENSITEK 2018 STMIK Pontianak," vol. 12, pp. 1-6, 2018.

[4] A. Levchenko, "Additive manufacturing as a mean of rapid prototyping: from words to the actual model," Saimaa University of Applied Sciences, 2015.

[5] I. Hager, A. Golonka, and R. Putanowicz, "3D Printing of Buildings and Building Components as the Future of Sustainable Construction?," Procedia Eng., vol. 151, pp. 292-299, 2016.

[6] L. G. Blok, M. L. Longana, H. Yu, and B. K. S. Woods, "An investigation into $3 \mathrm{D}$ printing of fi bre reinforced thermoplastic composites," vol. 22, no. May, pp. 176-186, 2018.

[7] B. I. Oladapo, S. A. Zahedi, and A. O. M. Adeoye, "3D printing of bone scaffolds with hybrid biomaterials," Compos. Part B Eng., vol. 158, no. July 2018, pp. 428-436, 2019.

[8] S. R. Rajpurohit and H. K. Dave, "Impact of Process Parameters on Tensile Strength of Fused Deposition Modeling Printed Crisscross Poylactic Acid," vol. 12, no. 2, p. 6, 2018.

[9] ASTM D638 - 14, "Standard Test Method for Tensile Properties of Plastics 1," 2015.

[10] S. Farah, D. G. Anderson, and R. Langer, "Physical and mechanical properties of PLA, and their functions in widespread applications - A comprehensive review," Adv. Drug Deliv. Rev., vol. 107, pp. 367392, 2016. 